\title{
Steroid-Induced Psychosis Presenting as "Alice in Wonderland" Syndrome
}

\author{
Vinobha Gorriah M.D. \\ UMDNJ - Robert Wood Johnson Medical School, Piscataway, NJ; Trenton Psychiatric Hospital, West \\ Trenton, NJ
}

Frank W. Favazza M.D.

VA Medical Center, Lyons, NJ

Migdalia Fort-Ramirez M.D.

Mental Hygiene Clinic, VA Medical Center, Lyons, NJ

Follow this and additional works at: https://jdc.jefferson.edu/jeffjpsychiatry

Part of the Psychiatry Commons

Let us know how access to this document benefits you

\section{Recommended Citation}

Gorriah, Vinobha M.D.; Favazza, Frank W. M.D.; and Fort-Ramirez, Migdalia M.D. (1996) "Steroid-Induced Psychosis Presenting as "Alice in Wonderland" Syndrome," Jefferson Journal of Psychiatry. Vol. 13 : Iss. 1 , Article 7.

DOI: https://doi.org/10.29046/JJP.013.1.006

Available at: https://jdc.jefferson.edu/jeffjpsychiatry/vol13/iss1/7

This Article is brought to you for free and open access by the Jefferson Digital Commons. The Jefferson Digital Commons is a service of Thomas Jefferson University's Center for Teaching and Learning (CTL). The Commons is a showcase for Jefferson books and journals, peer-reviewed scholarly publications, unique historical collections from the University archives, and teaching tools. The Jefferson Digital Commons allows researchers and interested readers anywhere in the world to learn about and keep up to date with Jefferson scholarship. This article has been accepted for inclusion in Jefferson Journal of Psychiatry by an authorized administrator of the Jefferson Digital Commons. For more information, please contact: JeffersonDigitalCommons@jefferson.edu. 


\title{
Steroid-Induced Psychosis Presenting as 'Alice in Wonderland' Syndrome
}

\author{
V. Gorriah, M.D., F.W. Favazza,M.D., \\ M. Fort-Ramirez, M.D.
}

\begin{abstract}
A 40 year old overweight male with a history of bronchial asthma, hypertension, and "schizophrenia" was admitted for intractable bronchial asthma. He did not have a history of drug or alcohol use.

Upon admission, he was treated with high doses of $I V$ methyl prednisone, oral prednisone, and triamcinolone inhaler. He developed complex visual hallucinations which decreased following tapering of prednisone and discontinuation of the triamcinolone. EEG showed diffusue slowing suggesting a toxic metabolic state.
\end{abstract}

\section{INTRODUCTION}

The syndrome of Alice in Wonderland is a symptom complex characterized by hallucinations of the sense of body image. This conglomeration of symptoms was first reported in 1952 by Lippman whose patient described feeling short and wide as she walked along, like "Tweedle Dum or Tweedle Dee" (1). Todd coined the term "The syndrome of Alice in Wonderland" (2) to describe these subjective bizarre experiences in non-neurotic people, plagued by concerns of their own sanity. The symptoms included visual hallucinations, illusions, feelings of levitation and "illusory alterations in the sense of the passage of time." Alice in Wonderland is the story of the fantastic adventures of Alice authored by Charles Dodgson, under the pseudonym Lewis Carroll. There has been speculation that the "visual imagery and other bizarre phenomena" described is the subjective experience of Dodgson who suffered from migraine headaches, though he developed migraine headaches much after he had written this book (3). The condition has been described in conditions such as migraines, epilepsy, and viral encephalitis (4). It has also been implicated in intoxication due to drugs like mescaline, LSD, marijuana, and in alcohol delirium. The syndrome has also been described in hypnotic states, hypnagogic hallucinations,

Vinobha Gooriah, M.D. is a third year resident in psychiatry at UMDNJ-Robert Wood Johnson Medical School, Piscataway, NJ. At the time of writing this article, he was a second year resident at Trenton Psychiatric Hospital, West Trenton, NJ.

Frank W Favazza, M.D. is acting director at the VA Medical Center at Lyons, NJ. He was chief of consultation-liaison at the time the case was written.

Migdalia Fort-Ramirez, M.D. is the head of the Mental Hygiene Clinic, the outpatient psychiatry unit at the VA Medical Center at Lyons, NJ. 
schizophrenia, and in some cerebral lesions. Cinbis and colleagues describe visual metamorphopsia in the patient's perception of others (5). Visual metamorphopsia is a perceptual disturbance wherein another person, object, or part thereof is perceived as changing in size or shape in presence of the observer. The classical syndrome has been reported in documented EBV infection (6). Lippman, Copperman \& Golden all believe that the pathology lies in the posterior parietal lobe, though metamorphopsia in this syndrome has itself been described as resulting from migrainous ischemia (7). A review of the literature indicates that this syndrome has never been described in conjunction with the use of steroids. The following case study is an example of the Alice in Wonderland syndrome following treatment with steroids.

\section{CASE}

$\mathrm{Mr}$ "X" was a 40 year old male who had a five year history of bronchial asthma and a three year history of hypertension. He came to the hospital with complaints of shortness of breath of seven days duration.

\section{HISTORY OF PRESENT ILLNESS}

$\mathrm{Mr} \mathrm{X}$ was admitted to the medical unit through the emergency room. While under treatment there, a psychiatric consult was requested as patient started having hallucinatory experiences.

\section{BACKGROUND INFORMATION}

The patient stated that he was diagnosed with bronchial asthma in 89 but because he was not responsive to the anti-asthmatic medications prescribed (see details under past medical history), he was started on $20 \mathrm{mg}$ of prednisone per day. Frequent exacerbation of asthma necessitated increasing his dose to $60 \mathrm{mg}$ of prednisone per day. Attempts to taper the steroid, even after eight months of treatment proved futile. The patient stated that he had never been off steroids for more than one month since the treatment was started. He also stated that when his shortness of breath became unbearable he would increase his prednisone on his own. Two and a half years ago, he developed headaches, preceded by flashes of light and halos. Six months after their first onset, the headaches disappeared spontaneously and he started hearing "noises and stuff like that." These transformed into voices, at times "as clearly as I hear you now" and, at times, "mumbo-jumbo." He denied extra-campine hallucinations, i.e. being able to "see" whispered voices coming from behind him, or any thought echo. He always heard one voice at any one time, with rare, resistible commands to hurt himself and his wife. These auditory hallucinations also had frequent derogatory tones.

He sought psychiatric help, was admitted as inpatient and treated with thiothixene which was increased to $10 \mathrm{mg}$ b.i.d. $20 \mathrm{mg}$ h.s. and discharged on the same medication. He reported not being "bothered" by the voices though they were still 
present. After another six months had passed, he started having vivid visual hallucinations. At that time, his medications included prednisone $60 \mathrm{mg}$ per day, triamcinolone and salbutamol inhalers, thiothixene, buspirone, Lisinopril, pseudoephedrine, beclomethasone aqueous; cimetidine $300 \mathrm{mg}$ b.i.d. was started as prophylaxis against possible prednisone side effects.

\section{PAST MEDICAL HISTORY}

Mr X recalled having developed renal tubular acidosis as a child. He was not sure as to how he was treated. He also stated having his tonsils removed. The patient had an episode of loss of consciousness at the age of 17 and on two subsequent occasions. Seizure disorder was ruled out and no further intervention was warranted. He had no history of head trauma or headaches. In 1987, he sustained a collar bone fracture secondary to a motorcycle accident. In July 1988 he developed bronchial asthma following "an epidemic of flu." The patient stated that he was treated with theophylline $300 \mathrm{mg}$ t.i.d. and salbutamol $4 \mathrm{mg}$ q.i.d. In September of the same year, as his asthma was not being relieved, $20 \mathrm{mg}$ of prednisone per day was added to his existing medication regimen. He was later found to have hypertension and received $12.5 \mathrm{mg}$ of hydrochlorothiazide on a daily basis. In 1990 he was admitted three times as inpatient and treated for asthma with theophylline $300 \mathrm{mg}$ t.i.d., prednidone $20 \mathrm{mg}$ q.d., salbutamol $4 \mathrm{mg}$ q.i.d., salbutamol nebuliser, $125 \mathrm{mg}$ bolus methyl prednisone on admission. Each time his prednisone was increased to $60 \mathrm{mg}$ and subsequently tapered down to $20 \mathrm{mg}$. Mr X denied prior history of bronchial asthma or respiratory infection. He admitted to being allergic to pollen.

\section{PAST PSYCHIATRIC HISTORY}

The patient denied any history of psychiatric illness. He, however, admitted to getting anxious when overwhelmed by his work and studies. He denied physical or sexual abuse, use of drugs, cigarettes, or alcohol.

After his hallucinations started, Mr X received various tentative diagnoses among which were schizophreniform disorder, schizoaffective disorder, schizophrenia, Factitious disorder with psychological stress, dysthymia, and organic hallucinosis. He was treated successively with thiothixene, perphenazine with trihexyphenidene, and then haloperidol with benztropine. No neuroleptic seemed to help with his psychosis.

\section{FAMILY HISTORY}

Mr X's 77 years old father had hypertension, stroke, and myocardial infarction. He was self-employed at his own restaurant business prior to his retirement. The patient's mother was 73 and healthy. He had three siblings, a 50 year old brother, and two sisters aged 37 and 33 . They were all healthy. The patient denied any history of psychiatric illness in the family. 


\section{PSYCHOSOCIAL HISTORY}

The patient described an uneventful childhood with no history of physical or sexual abuse. He interacted well with siblings and peers and was an "A" student. Mr $\mathrm{X}$ stated that his mother "had high expectations and demands. She always came too hard on me."

Mr X completed high school, worked in a paper mill for one year before joining the family restaurant business. He got married to a medical technician at the age of 27. The family business collapsed and the patient joined the army from where he was discharged on medical grounds in 1990. After a short period of unemployment the patient started working as a security guard while attending college. The patient's wife was studying for her RN. The couple had two healthy children aged 13 and 10 years.

\section{MENTAL STATUS EXAMINATION}

Mental status examination showed a 40 year old caucasian male appearing his stated age, obviously anxious with fine tremors of the fingers and a tremulous voice. His affect was blunted. He was cooperative, coherent, and his stream of thought was goal-directed. He had good attention span and concentration and showed above average intelligence with preserved cognitive functions. He described auditory and visual hallucinations (details of which are provided under hospital course) while being aware that they existed only "in my imagination." He denied suicidal or homicidal ideation. His insight and judgement were reasonable.

\section{HOSPITAL/CLINIC COURSE}

Upon admission, the patient was started on methyl prednisone $125 \mathrm{mg}$ IVPM in addition to his other medications including $60 \mathrm{mg}$ of prednisone q6h. The next day after initiation of the solu-medrol, he gave a dramatic description of his hallucinations. He saw figures floating all over the place. He stated that he saw normal people who would suddenly attain gigantic proportion (macropsia) and the next moment turn into miniature living actors, a phenomenon described as micropsia or lilliputian hallucinations. He saw people zooming close and far, mostly staying the same size and always staying in focus (autoscopic hallucinations; poropsia). He described different colors of light converging and assuming different shapes, like giraffes, elephants (zoopsia), and people. At other times, he saw tiny figures jumping out of the garbage bag and playing around. At one time, during an interview, he had the illusion that "look, there is a baby wrapped in the bedsheet." He said: "I can't tell the illusions from reality." All the while he retained clear sensorium, could sustain a long conversation with good attention span and concentration, even when actively hallucinating. At another time, however, he ran out of the unit saying "My cousin and my uncle have left the bike outside and I have to go and get it." He responded to re-direction. At this time, prednisone was slowly tapered and cimetidine was discon- 
tinued. His thiothixene was changed to haloperidol and he also was given benztropine, triamcinolone and ventolin inhalers. The hallucinations persisted.

After triamcinolone was discontinued, the patient reported that his hallucinations had decreased, but were still present. As he approached discharge, he had an exacerbation of his asthma and he was put on triamcinolone again. Mr X reported an increase in the intensity of his hallucinations, with auditory command hallucinations to hurt his wife. He also described figures from the picture on the wall coming out towards him. He had one episode of derealization; questioned as to where he was going one day, he stated he was looking for the restroom and did not know where he was. The azmacort was discontinued and over the succeeding days, he found that the hallucinations had tempered down significantly, and though still present, were not bothering. He reported feeling weak, having muscle aches and to be moving as if "in slow motion."

Psychological evaluation suggested the presence of an "acute psychotic episode in an individual who has been mostly functional until recently."

A thorough medical work-up including pulmonary function tests, CG Scan of the head without contrast, EEG with photic stimulation was essentially normal with the exception of diffuse slowing on EEG compatible with a toxic metabolic state. Laryngoscopy showed vocal cord dysfunction, specifically an incomplete closure of the vocal cord on inspiration. He was discharged and given an outpatient follow-up appointment.

\section{DISCUSSION}

It is interesting to note that the patient's rather distressing condition included migrainous headaches followed by auditory hallucinations, visual hallucinations, and illusions. The symptoms began about six months after he was started on high doses of steroids. Though cimetidine is strongly implicated in the causation of psychosis the patient was started on cimetidine after his hallucinations had begun. Discontinuation of cimetidine did not result in any alteration of symptoms. The patient seemed most concerned with his visual misperceptions. This caused considerable anxiety, to which he was premobidly prone, and he started having doubts about his sanity. Interestingly restarting triamcinolone seemed to kindle and aggravate a psychosis which had started tempering down.

Steroid-induced psychosis is a toxic psychosis that manifests through a variable spectrum of presentation (8). Rome and Braceland categorized this into four grades ranging from the mildly euphoric to the floridly psychotic (9). The side effects of steroid use can be broadly classified into medical complications and psychiatric complications. The medical complications consist of weight gain, edema, menstrual irregularities, hypertension, Addisonian crisis, osteoporosis, dyspepsia, peptic ulcers, and secondary infection (10). The psychiatric complications consist of anxiety, emotional lability, pressured speech, marked distractability, feeling of sensory flooding, disturbance of body image, and hallucinations. Confusion, agitation, perplexity, tearfulness, aimless wandering, suicide, homicide and paranoid angry depression are 
other psychiatric side effects (8). A dementia-like syndrome has also been described (11).

Severe psychiatric reactions occur in approximately $5 \%$ of steroid treated cases (12). The Boston Collaborative Study gives a figure of $3 \%$ for the incidence of steroid-induced psychosis. The duration of steroid treatment prior to the onset of psychiatric symptoms has ranged from 1-210 days with a mean age of onset of 39.6 years, though age itself is not felt to be a risk factor (12). The probability of developing a psychotic reaction when using prednisone is highest at doses above 40 $\mathrm{mg} /$ day (13). This is supported by the data of Hall et al (8).

Mental changes that occur during the course of treatment with steroids may be merely responses to changes in physical symptoms or just minor alterations in existing psychiatric disturbances. Patients with unstable personalities or with a history of mental illness are not necessarily predisposed to developing untoward psychiatric symptoms (14).

In their study of 150 cases of steroid psychosis, Braunig and colleagues found that $17 \%$ presented with suicidal behavior: 15 patients showed suicidal ideation, 8 attempted and 3 committed suicide (15).

The prognosis of steroid psychosis is generally a good one with full remission following discontinuation or dimunition of steroid dosage (9). In their study, Lewis and Smith found that $93 \%$ of cases attain complete recovery, $4 \%$ have continued or recurrent psychiatric symptoms, and 3\% committed suicide (12). The treatment modalities suggested are: steroid taper and discontinuation, steroid taper and discontinuation with concommittent low dose neuroleptic, and ECT for persistent and unresponsive affective psychoses. Tricyclic antidepressants may aggravate steroid psychosis. For those patients who have potentially life-threatening conditions and for whom steroid therapy is necessary, prophylactic lithium may be instituted to minimize the chances of developing steroid psychosis (16). This then becomes a matter of speculation. There is no way of knowing who among such individuals would be prone to developing psychosis.

\section{CONCLUSION}

Steroid-induced psychosis presents with a spectrum of symptoms. As such, a presentation like "Alice in Wonderland" syndrome can be confused with schizophrenia or temporal lobe epilepsy. Clinicians should be aware that some medications including steroids and cimetidine can cause different types of psychoses and mimic schizophrenia. Careful history, corroborated with evidence from old charts would provide information that could assist in making a correct diagnosis. It appears that certain people have a lower threshold for developing psychosis. In the case study presented, it may have been that once EEG changes occurred, the patient's threshold was so much lowered that a minuscule dose of steroids kindled psychosis. More observations are required to substantiate this finding. What makes this case so interesting is that the patient's psychotic symptoms were mis-diagnosed as schizophrenia. 


\section{ACKNOWLEDGEMENT}

Lynn Fellows, the librarian at the VA Medical Center at Lyons provided valuable help in conducting the literature search.

\section{REFERENCES}

1. Lippman CW: Certain hallucinations peculiar to migraine. J Nerv Ment Dis 1952; 116:346.

2. Todd J: The Syndrome of Alice in Wonderland. Can Med Ass J Nov 1, 1952; 73:701-704.

3. Murray TJ: The Neurology of Alice in Wonderland. Can J Neurological Sciences Nov 1982; $454-456$.

4. Copperman SM: "Alice in Wonderland" syndrome as a presenting symptom of infectious mononucleosis in children. Clin Pediatr 1977; 16:143-146.

5. Cinbis M, Aysun S: Alice in wonderland syndrome as an initial manifestation of EbsteinBarr virus infection. Brit J of Ophthal 1992; 76(5):316.

6. Shii-Ben Liaw, Ein-Yiao Shen: Alice in wonderland syndrome as a presenting symptom of EBV infection. Pediatr Neurol 1991; 7:464-466.

7. Rolak LA: Literary Neurologic Syndromes. Arch Neurol 1991; 48(6): 649-651.

8. Hall Richard CW, Popkin Michael K et al: Presentation of the steroid psychoses. J Nerv Ment Dis Apr 1979; 167(4):229-236.

9. Rome HP, Braceland FJ: The psychological response to ACTH, cortisone, hydrocortisone, and related steroid substances. Amer J Psychiatry 1952; 108:641-651.

10. Treadwell BLJ, Sever ED, Savage O: Side-effects of long term treatment with corticosteroids and corticotrophin. The Lancet May 1964; 1121-1123.

11. Varney NR, Alexander B, MacIndoe JH: Reversible steroid dementia in patients with steroid psychosis. Amer J of Psychiatry 1984; 141:369-372.

12. Lewis DA, Smith RE: Steroid-induced psychiatric syndromes. J of Affective Disorders 1983; 5:319-332.

13. The Boston Collaborative Drug Surveillance Program: Acute adverse reaction to prednisone in relation to dosage. Clinical Pharmacology and Therapeutics 1972; 13:694-697.

14. Lewis A, Fleminger JJ: The psychiatric risk from corticotrophin and cortisone. The Lancet Feb 20, 1954; 383-386.

15. Braunig P, Bleistein J, Rao ML: Suicidality and corticosteroid-induced psychosis. Biological Psychiatry June 1989; 26(2):209-210.

16. Davis JM, Leach A, Merck BS, Janicak PG: Treatment of steroid psychoses. Psychiatric Annals 22/(Psychopharmacology update) Sept 1992; 487-491. 